\title{
Sombreando Don Segundo Memória e Intertextualidade em Ricardo Güiraldes
}

\author{
Joana Bosak de Figueiredo ${ }^{1}$
}

Résumé: Cet article étude la mémoire dans l'intertextualité utiliseé par Güiraldes. On veut récuperer son chemin argentin à travers la "bibliothèque de nostalgie intellectuelle" (ombre) de sa vie aux champs (la mémoire).

Mots-clés: Güiraldes, Don Segundo Sombra, mémoire, intertextualité, identité

Resumo: Este artigo busca, através dos processos textuais, rastrear a memória na intertextualidade guiraldiana, buscar, na sua biblioteca intelectual a nostalgia (sombra) de sua vida campeira/verdadeira (memória), para assim recompor seu percurso de argentino após ter todas as nacionalidades.

Palavras-chave: Güiraldes, Don Segundo Sombra, memória, intertextualidade, identidade

\section{Reconsiderando Don Segundo Sombra}

O texto que se segue é uma interpretação possível com tentativas de melhor compreender os processos intertextuais de um de meus objetos de tese: o romance Don Segundo Sombra, do escritor 'argentino'2 Ricardo Güiraldes, escrito entre Paris e San Antonio de Areco, interior da província de Buenos Aires, entre 1919 e 1926. Levanto algumas questões suscitadas em aulas de Teoria Literária no doutorado em literatura Comparada da UFRGS.

Dada a impossibilidade de conseguir alimentar-me, como o desejado, de todas as idéias e (inter)textos disseminados em aulas (e fora delas) serem apropriados para o trabalho fiz uma seleção muito aquém do que gostaria. A riqueza das questões teóricas propostas pelas disciplinas ainda estão em processo de devoração ${ }^{3}$. Portanto, o que se esboçará a

1 Mestre em História, Dra. em Literatura Comparada, sob orientação da Profa. Patrícia Lessa. Foi professora de História do Rio Grande do Sul no Departamento de História da UFRGS e no setor de Teoria Literária no Instituto de Letras da mesma universidade. Participa do grupo de estudos na área de tradução no convênio entre UFRGS e Universitat de Barcelona, onde esteve em estágio doutoral. Escreve como colunista para os sites Modamanifesto.com e do Centro de Estudos de Literatura e Psicanálise Cyro Martins - celpcyro.org.br. Atualmente pesquisa, além dos estudos de tradução e de identidade regional, a história social da moda e suas relações com a literatura.

2 No decorrer do texto acredito que ficará claro que Güiraldes é um autor sem fronteiras e transfronteiras.

3 A devoração de que aqui se fala tem o sentido impresso por Oswald de Andrade, em seu Manifesto Antro- 


\section{Conexão Letras}

seguir é um mosaico ainda muito restrito de minhas citações, coletadas em aula e nos textos lidos. Minha biblioteca pessoal cresceu significativamente.

A idéia inicial para esta reflexão, de abordar os dois conceitos mais amplamente trabalhados na disciplina (além da intertextualidade, a interdisciplinaridade) foi abandonada na sua forma mais explícita. Entretanto, percebi que qualquer ensaio ao qual me proponha dentro de meu objeto terá uma característica interdisciplinar, haja vista a permanência de minha “origem" e meus primeiros textos fundadores, que não serão "renegados". Não é o que quero. A interdisciplinaridade só soma e o universo de possibilidades suscitado pelo comparatismo vai muito além da permanência em uma ou outra margem do rio. A terceira margem é sempre mais produtiva. O movimento pendular sempre será feito, pois é cada vez mais difícil, felizmente, manter a Literatura Comparada "confinada"4.

Memória, Intertexto, Sombra

Sinônimos para o mesmo do outro no comparatismo

\section{Memória}

Amar o perdido

deixa confundido

este coração.

Nada pode o olvido

contra o sem sentido

apelo do Não.

As coisas tangíveis

tornam-se insensíveis

à palma da mão.

Mas as coisas findas, muito mais que lindas, essas ficarão.

Carlos Drummond de Andrade

Aquilo que se distanciava era mais uma idéia que um homem. Fábio Cáceres - Ricardo Güiraldes

pofágico, de uma assimilação transformadora dos textos lidos, o que mais tarde será abordado por Leyla Perrone-Moisés como mais uma forma de intertextualidade, cunhada avant la lettre, no Brasil, em 1928. Ver: ANDRADE, Oswald. A utopia antropofágica - obras completas. São Paulo: Globo, 1990. E ainda: PERRONE-MOISÉS, Leyla. Literatura Comparada, Intertexto e Antropofagia. In: . Flores da Escrivaninha. São Paulo: Companhia das Letras, 1990.

4 O termo confinamento é utilizado pelo sempre muito crítico René Wellek em seu famoso manual de literatura

- Teoria da Literatura. Ver: WELLEK, René \& WARREN, Austin. Teoria da Literatura. Lisboa: Publicações Europa-América, 1955 ( $3^{\mathrm{a}}$ ed.), pp. 53-62. 
O que fica, quando tudo acaba, é a memória, como quer Drummond, e o olvido, para Borges em Un Lector (de Elogio de la Sombra). O romance Don Segundo Sombra (a idéia mais que o homem), é o que ficou, para seu narrador, Fábio Cáceres, e para seu autor, Ricardo Güiraldes. Rememorar a construção de sua identidade, para Fábio e construir o fragmento mais antigo e fundamental da sua e da (identidade) argentina, foi o que fez Ricardo Güiraldes. Don Segundo (Don Segundo Ramírez) é sombra porque é o intertexto de Fábio Cáceres e de Ricardo Güiraldes. É o outro do mesmo: é a sombra, o vago da velhice de Güiraldes ${ }^{5}$ e a nostalgia da juventude de Cáceres ${ }^{6}$ - é o momento em que se obscurece a memória e quando, consequentemente, as portas estão abertas para a entrada do imaginário. E como em prosa é mais difícil de "outrar”, o texto de Güiraldes é às vezes quase uma poesia - "Alvorecia e já pela pequena janela vi orvalharem-se de matizes dourados as nuvens do nascente compridas e finas como pétalas de girassol"' - as vezes quase um desenho, porque as paisagens por ele descritas vão-se pintando em nossa mente a medida que o lemos e o sofremos: "O caminho diante de mim estendia-se escuro. O céu, ainda zarco de crepúsculo, refletia-se nos charcos de forma irregular ou nas águas empoçadas nos profundos carris de alguma carreta, em cujos sulcos tomava aspecto de aço cuidadosamente recortado." 8

Ao final, sangramos juntos 9 .

Texto refundador da memória e da identidade argentinas é ele mesmo memória e nostalgia do narrador-autor. Se o narrador, Fábio Cáceres, busca encontrar-se na sua trajetória de guacho a gaucho através dos ensinamentos de Don Segundo e acaba por tornar-se um homem culto e experimentado, é porque Güiraldes soube, em sua narrativa, ultrapassar a dicotomia civilização versus barbárie diagnosticada por Sarmiento em $1845^{10}$, que cindia a Argentina em dois mundos (o bárbaro, representado pelo pampa dos gauchos e caudillos e o civilizado, da cosmopolita Buenos Aires dos anos 1910/20) e o gaucho malo de Martín Fierro $^{11}$ (malo porque obra de uma civilização que o oprimiu e excluiu).

A estudiosa da obra guiraldiana, Nilda Díaz, em Pampa y Camino $^{12}$, elucida esta questão:

Encontrar un arquetipo de lo nacional era lancinante preocupación de Lugones, y no sólo la suya; la de Güiraldes, recuperar ese tiempo que se le había escurrido de entre las manos, cuando la muerte venía ya aguaitándolo. No, Martín Fierro, escrito

5 O romance é concluído em 1926, quando Ricardo Güiraldes já está muito doente, vindo a morrer poucos meses depois, em 1927, em Paris. Apesar de ter morrido jovem (nasceu em 1886), sua "velhice" é justamente ao escrever a obra-prima, os sete últimos anos de sua vida (1919-1926).

6 O narrador, Fábio Cáceres, só conta sua história (memória) após a escolha de ser proprietário e a despedida de Don Segundo Ramírez, seu padrinho, de quem era a sombra. A cena final desenha um pôr do sol com Don Segundo indo embora numa coxilha, ele mesmo uma sombra, ele mesmo o mito.

7 GÜIRALDES, Ricardo. Don Segundo Sombra. Porto Alegre: L\&PM, 1997. Tradução de Augusto Meyer. P. 36

8 Idem, p. 19.

9 A última frase de Fábio Cáceres (Güiraldes), em Don Segundo Sombra, é: "Me fui, como quem se dessangra" ou "Fui-me, como quem sangra", dependendo da edição em português. Na primeira versão, a tradução de Augusto Meyer foi revista por Aldyr Schlee, na segunda, é o texto de Meyer.

10 SARMIENTO, Domingo Faustino. Facundo: civilização e barbárie no pampa argentino. Porto Alegre: EDIPUCRS/Editora da UFRGS, 1996.

11 HERNÁNDEZ, José. Martín Fierro. Buenos Aires: Karten, 1979.

12 DÍAZ, Nilda. Pampa y Camino. In: GÜIRALDES, Ricardo. Don Segundo Sombra. Edición crítica, Paul Verdevoye, coordinator, $1^{\text {a }}$ reimp. Madrid; Paris; México; Buenos Aires; São Paulo; Lima; Guatemala; San José de Costa Rica; Santiago de Chile: ALLCA XX, 1997. 
'para mostrar que el ministerio de Guerra (...) hacía del gaucho un desertor y un traidor', según la afirmación de Borges, no es Don Segundo Sombra. Este hombre no tiene ningún problema com la justicia ni com su contorno físico ni humano; a través de él Güiraldes mitificava a un ser que existió, que ya no existía, reelaborada su propia infancia, manejaba com excelsa perfección las metáforas obsesivas que jalonan buena parte de su reducida obra. Por encima de toda outra consideración, Don Segundo Sombra es el formidable testimonio de una pasión, la historia de amor entre un hombre y su tierra. ${ }^{13}$

E é justamente na descrição das paisagens do pampa, das várzeas de seus sonhos e do aprendizado das lidas pastoris, que Fábio Cáceres vai-se fazendo, pouco a pouco, simultaneamente gaucho e homem, sempre sob o olhar atento de seu "pai adotivo", Don Segundo; o mito, o ídolo. Ao mesmo tempo, Ricardo Güiraldes torna-se gaucho e argentino, tendo por perto Segundo Ramírez, o homem, o símbolo, o cíclope de Ernesto Sábato:

Un crítico argentino, que pretende utilizar a Marx como maestro, sostiene que el Don Segundo Sombra de Güiraldes no existe, que es apenas la visión que un estanciero tiene del antiguo gaucho de la provincia de Buenos Aires; lo que es más o menos como acusar a Homero de falsificador porque exhaustivos registros llevados a cabo en las montañas calabresas y sicilianas no hán dado com un solo cíclope. Com este mismo criterio de naturalista habría que rechazar a Modigliani por su manía de pintar mujeres com gargantas inexistentes. Pero inexistente dónde? No desde luego en el espíritu del pintor. La diferencia entre Modigliani y una máquina fotográfica es que el arte no es una mera copia de la realidad externa sino un acto onto-creador, más cercano al sueño que al espejo. ${ }^{14}$

Como bem diz Sábato, Don Segundo não é o espelho que viu Ricardo Güiraldes no pampa argentino, mas o produto de uma vivência amorosa do escritor por sua terra e suas gentes, sonhado por sete anos seguidos de escritura nem sempre "produtiva", mas vivida.

Durante uma das estadas em La Porteña, quando já deveria estar terminando o livro, Güiraldes se descobre não escrevendo, mas vivendo Don Segundo: "No he trabajado esta tarde pero esto no me mortifica porque de la conversación com los reseros puedo servirme para Don Segundo Sombra. En todo caso me pongo en ambiente. ${ }^{15 "}$

Güiraldes, ao tornar-se gaucho depois de culto e cosmopolita e Fábio, ao tornar-se culto depois de guacho e gaucho, conseguem a façanha de sintetizar passado e presente argentinos e, quem sabe, romper com a dicotomia sarmienteana. $\mathrm{O}$ resultado da transcendência desses dois mundos sem harmonia foi a constituição do gaúcho no entre lugar.

Don Segundo reconhece a tradição e a sabedoria campeiras, que passa ao guacho Fábio. O rapaz, enquanto se faz homem, apreende os valores de seu tutor: é um verdadeiro gaúcho, sabe das lidas campeiras sem envolver-se em brigas e confusões. Ao ter de escolher entre seguir errando e fincar raízes na estância de seu pai revelado, ao conhecer sua "verdadeira" identidade e deixar de ser, finalmente, um guacho, torna-se não apenas filho legítimo e proprietário, mas um homem culto, que não somente lê, mas o faz em francês.

Não por acaso, essa é a trajetória de Güiraldes, porém às avessas. O autor passa os primeiros anos de vida na Europa, aprendendo antes o francês e o inglês do que o espanhol.

13 DÍAZ, op. cit., p. 294.

14 SÁBATO, Ernesto. Mito y realidad de Don Segundo Sombra. In: GÜIRALDES, op. cit., p. XV.B

15 Excerto do diário de Ricardo Güiraldes, em 18 de maio de 1924. In: GÜIRALDES, Op. cit., p. 257. 
Entre suas andanças, vai de Buenos Aires a Paris. Corresponde-se com poetas franceses, lê e publica em órgãos de divulgação europeus, traduz, conjuntamente com o grupo de Proa $^{16}$ Gide, Valéry, Claudel, Fargue, Girardoux, Joyce, Larbaud, Romains, SaintlégerLéger ${ }^{17}$. Conhece toda a América, principalmente a Central, de onde escreve suas primeiras memórias ${ }^{18}$. É um verdadeiro andarengo ${ }^{19}$-cosmopolita.

Em sua estada maior em Buenos Aires integra-se aos movimentos vanguardistas da época no Rio da Prata. Entra em contato com Horacio Quiroga, Ricardo Piglia, Leopoldo Lugones e Jorge Luis Borges, entre outros, ao ingressar nos movimentos Ultra, Martín Fierro e Proa, do qual é o principal mentor. E é justamente em seus últimos anos, na fazenda de seu pai, no interior da província boinarense, em San Antonio de Areco (onde Fábio Cáceres "vive"), que se torna gaucho, ao escrever, durante sete anos, sua obra maestra. Güiraldes morre pouco depois, em Paris. Morreu gaucho. Foi seu percurso em busca de si mesmo que o fez procurar Don Segundo Sombra na prosa. Antes, passeou, e muito, pelo alheio.

Hugo Rodríguez-Alcalá, ao argumentar a favor da experiência de vida de Güiraldes como fundamental à construção de Don Segundo Sombra tal como o fez ${ }^{20}$, em Destinos ${ }^{21}$, explica a existência da percepção do universal no local e do jogo de "luzes e sombras" de espelhos e duplos na obra:

Lo que suele desconcertar al crítico superficial que, incapaz de comprender la complejidad de una obra tan sencilla y diáfana en apariencia, Da Cal lo capta como su virtud artística más sobresaliente. Percibe él com lucidez la trasposición de lo local en lo universal, un virtud de una 'serie de sutiles dualidades, de constantes desdoblamientos, en una técnica de espejos, en que las imágenes reales de una realidad estilizada, ideal, estéticamente deshumanizada, mejor diremos - para acompañar la intención del autor - en una serie de sombras que se proyectan agrandadas y puras hacia el terreno de los valores absolutos'. Esta observación, de una sagacidad tan filosófica explica la desazón del crítico miope que, en los gauchos de Güiraldes, se niega a aceptar criaturas ficticias quintaesenciadas por el arte, y exige que Güiraldes nos hable de problemas económicos de Don Segundo, de sus preocupaciones familiares, y se indigna cuando el héroe gaucho se le agranda, de súbito, misteriosamente, contra el horizonte luminoso. ${ }^{22}$

Os críticos da época, em grande parte, não conseguiram perceber Don Segundo Sombra, por mais autobiográfico que fosse, como uma obra de arte, como o resultado de uma reflexão poética sobre a educação de um rapaz, a busca de identidades, fossem indi-

16 Proa é o grupo e editora criados por Güiraldes e outros escritores em 1925 e especial seleção de autores latino-americanos. Entre esses, os que subscrevem o primeiro documento ou fazem parte do movimento: Jorge Luis Borges, Brandán Caraffa, Pablo Rojas Paz, Cansinos Assens, Andrés L. Caro, Macedonio Fernández, Oliverio Girondo, Ramón Gómez de la Serna, Pedro Leandro Ipuche, Keller Sarmiento, Valery Larbaud, Eugenio Montes, Pablo Neruda, Alonso Quesada, Alfonso Reyes, Salvador Reyes, Fernán Silva Valdés, Guillermo de Torre. Citado por BLASI, Alberto. Güiraldes: vida y escritura. In: GÜIRALDES, Op. cit., 250.

17 Idem, p. 252.

18 Podemos considerar "Xaimaca" como tal, já que diz respeito a anotações de viagens pela América Central. Ver: GÜIRALDES, Ricardo. Xaimaca. Buenos Aires: Editorial Losada, 1953 (2ªd.).

19 Andarengo bem poderia ser o mesmo que "errante" no vocabulário gauchesco.

20 Durante muitos anos a obra de Güiraldes foi duramente criticada por ser o autor um homem cosmopolita. O autor só era visto como um "afrancesado" que não teria nada a dizer sobre o pampa argentino e o gaúcho, por não ser um gaúcho "verdadeiro". Rodríguez-Alcalá acredita que é justamente a vivência internacional e regional de Güiraldes que tornou possível o seu olhar privilegiado sobre o local: justamente por conhecer o mundo e buscar no próximo de si as origens e o motivo de sua obra.

21 RODRÍGUEZ-ALCALÁ, Hugo. Destinos. In: GÜIRALDES, op. cit., pp. 271-285.

22 Idem, pp. 280-1. 
viduais, nacionais ou culturais, como modelos calcados em uma realidade completamente possível de ser copiada. Exigiam de Güiraldes comprovação, veracidade e enquadramento a uma norma pelo artista não pretendida. À exceção de poucos críticos, como Leopoldo Lugones, possivelmente o mais ardoroso defensor da época, e talvez Jorge Luis Borges, esta foi a recepção de Don Segundo Sombra em 1926 e arredores. Mal percebiam eles o alcance da obra, muito além do público "culto" das vanguardas rioplatenses:

\begin{abstract}
Ramón Cisneros, viejo capataz de La Porteña me decía: 'Tan bien que está el libro señora, el gaucho como es, el gaucho trabajador y honrao, no como en el Martín Fierro, el matrero, pendenciero, este es el gaucho de güena ley sencillo y trabajador... y cuando pelea es porque no tiene outro remedio, pa defenderse si señora el gaucho como no es más... Ricardo hablando com Don Segundo le explicaba que hay cosas en el libro que ni el las hay dicho y hecho. No es así? ${ }^{23}$
\end{abstract}

Ou seja, a obra acabou por incluir, a partir da estância La Porteña, um universo de leitores antes marginais, que se sentiam retratados na narrativa de Güiraldes e que conheciam o mundo do qual ele estava falando, bem como sua fonte de inspiração, o gaucho Segundo Ramírez. Além desta fala, é possível encontramos exemplares de Don Segundo Sombra ilustrados por um resero, desenhista autodidata que trabalhou em La Porteña e conheceu Don Segundo.

A obra é naturalmente intertextual porque dialoga não só como os textos güiraldianos anteriores, mas com os de seus colegas ultraistas, martinfierristas e de Proa e com seu maior amigo, Valéry Larbaud. Don Segundo, é claro, volta-se também aos exemplos já anteriormente referidos de Facundo e Martín Fierro. Antes de tudo, é uma telemaquia, pois é na viagem, no caminho, que Fábio torna-se, concomitantemente, homem e gaúcho.

Ainda são elementos constituintes fundamentais da escritura guiraldiana a música, presente em todo o texto, nas noites e no descanso dos gauchos, e a pintura, que é o que descreve as paisagens do romance. Diz Güiraldes: "Me gustaría pintar momentos"24

Há, também, a introdução de aspectos da cultura popular oral. O capítulo XXI, por exemplo, é todo ele dedicado à parábola "O ferreiro e a morte", contada por Don Segundo a Fábio, em mais um momento de aprendizagem.

Obra, autor e personagens estão no entre lugar. A síntese a que chegou Güiraldes é resultado da simultaneidade de processos por ele abarcados: romance, novela, poema, música, pintura, cartilha; o erudito e o popular; o rural e o cosmopolita; o universal no local. Vida e obra confundindo-se sempre na idéia que não há espaço intervalar neste caso; vida é obra, ou melhor: le livre fait le sens, le sens fait la vie. ${ }^{25}$

\title{
Intertexto
}

"Je savoure le règne des formules, le renversement des origines, la désinvolture qui fait venir le texte antérireur du texte ultérireur. Je comprends que l'oeuvre de Proust est, du moins pour moi, l'oeuvre de reférence, la mathésis géné-

23 Carta de Adelina del Carril, mulher de Güiraldes, ao melhor amigo do casal, o poeta Valéry Larbaud. Citada por BLASI, Alberto. Güiraldes: vida y escritura. In: GÜIRALDES, op. cit., p. 267.

$24 \quad$ Idem, p. 257.

25 BARTHES, Roland. Le plaisir du texte. Paris: Seuil, 1973, pp. 28-9. 
rale, le mandala de toute la cosmogonie littéraire - comme l'étaient les Lettres de Mme de Sévigné pour la gran-mère du narrateur, les romans de chevalerie pour Don Quichotte etc; cela ne veut pas du tout dire que je sois un "spécialiste" de Proust: Proust, c'est ce qui me vient, ce n'est pas ce que j'appelle, ce n'est pas une "autorité"; simplement un souvenir circulaire. Et c'est bien cela l'intertexte: l'impossibilité de vivre hors du texte infini - que ce texte soit Proust, ou le journal quotidien, ou l'écran télevisuel: le livre fait le sens, le sens fait la vie."

Roland Barthes, Le plaisir du texte

Roland Barthes, ao evocar a sua biblioteca particular no fragmento de Le plaisir du texte mostra a relevância da noção de intertextualidade em qualquer texto ou autor. Assim como Charles Baudelaire, em La Voix, a evocação das memórias literárias dos escritores está sempre e inexoravelmente presente em seu próprio texto. E é essa memória do texto que muitas vezes funciona como mola de criação, fazendo com que o autor, em sua rememoração rearticule significados recompondo seu próprio mosaico de citações. O intertexto é, desde a década de 1960 o conceito mais polêmico e discutido da Literatura Comparada.

Como já se disse anterioremente, a devoração de Güiraldes foi múltipla: textos europeus, latino-americanos, música (tango), poesia, viagens, correspodências intensas (como a que manteve durante anos com Valéry Larbaud). Sua rica vivência pessoal tornou possível a conjunção no texto de sua cultura incomum, oscilando entre o local e o universal, alternando ao longo de sua obra prosa e poesia, crônicas de viagens, ensaios críticos e ampla atividade editorial e participação em movimentos vanguardistas. Seu principal diálogo em Don Segundo Sombra foi com Martín Fierro, de José Hernádez, que é citado no decorrer do romance mas também nesta dedicatória:

'A Vd., Don Segundo.

A la memoria de los finados : Don Rufino Galván, Don Nicasio Cano y Don José Hernández.

A mis amigos domadores y reseros : Don Víctor Taboada, Ramón Cisneros, Pedro Brandán, Ciriaco Díaz, Dolores Juárez, Pedro Falcón, Gregorio López, Esteban Pereyra, Pablo Ojeda, Victorino Nogueira y Mariano Ortega.

A los paisanos de mis pagos.

A los que no conozco y están en el alma de este libro.

Al gaucho que llevo en mí, sacramente, como la custodia lleva la hostia.

Se o intertexto velado de Güiraldes em torno de sua vivência européia pode ser percebido através de diversas homenagens que faz (como nomear o capataz da fazenda em que originalmente trabalha Don Segundo - a que herda Fábio - de Don Valério. Homenagem a Valéry Larbaud, de quem era amicíssimo, ou a Paul Valéry, de quem leitor e tradutor, ou ainda, aos dois?) ao longo do romance, acredito que esta dedicatória, omitida em várias edições - como nas brasileiras, por exemplo - deixe entrever quais eram seus muitos interlocutores.

Eis aqui uma nova visão em relação à intertextualidade no caso de Güiraldes. Ao dizer que durante alguns meses se pôs no ambiente de Don Segundo, embora não o escrevesse tanto, Ricardo mostra outro tipo de diálogo que teve: com os amigos domadores, reseros e paisanos de seus pagos. A experiência obtida durante meses junto aos peões da 


\section{Conexão Letras}

estância de seus pais foi extremamente fecunda, pois as descrições da vida campeira que fez não soam artificiais e isto é avalizado, como já se viu, pelo próprio Ramón Cisneros, citado na dedicatória e em conversa com Adelina del Carril. Tal aproximação com a vida campeira contrariou o que diz Antonio Candido a respeito de obras regionalistas:

Nos livros regionalistas, o homem de posição social mais elevada nunca tem sotaque, não apresenta peculiaridades de pronúncia, não deforma as palavras, que, na sua boca, assumem o estado ideal de dicionário. Quando, ao contrário, marca o desvio da norma no homem rural pobre, o escritor dá ao nível fônico um aspecto quase teratológico, que contamina todo o discurso e situa o emissor como um ser à parte, um espetáculo pitoresco como as árvores e os bichos, feito para contemplação ou divertimento do homem culto, que deste modo se sente confirmado na sua superioridade. ${ }^{26}$

Como o emissor em Don Segundo é, ele mesmo, um homem originalmente pobre e cuja trajetória termina (na narrativa) ao tornar-se de posição social mais elevada, este estado ideal de dicionário não existe. $\mathrm{O}$ homem rural pobre aqui não é objeto de contemplação, mas o dono da história. E, no caso de Fábio, existe dúvida em relação à superioridade quando descobre-se herdeiro: « Imaginei que era um guri, um guacho desamparado, e que de súbito perdia aquilo a que vivera aferrado. ${ }^{27} \gg \mathrm{E}$ ainda :

Parece mentira; em lugar de alegrar-me pelas riquezas que me caíam das mãos do destino, entristecia-me pelas pobrezas que ia deixar. Por quê ? Porque atrás delas estavam todas as minhas lembranças de tropeiro andejo e, mais além, essa idefinida vontade de andar, que é como uma sede de caminho e uma ânsia de possessão, cada dia aumentada de mundo. ${ }^{28}$

O destino do verdadeiro gaúcho é a errância, o eterno trânsito em busca de novas tropilhas selvagens, pois pagos são pátria pequena, a verdadeira casa é o mundo, a ponto de Fábio pensar que deixará de ser gaúcho ao escolher pela propriedade: « - É verdade que já não sou o de sempre e que esses malditos pesos vão desmentir minha vida de paisano ? », ao que responde Don Segundo, sempre sábio: « - Olha - disse meu padrinho, apoiando sorridente a mão em meu ombro -, se és gaúcho às deveras, não hás de mudar, porque, aonde quer que vás, irás com tua alma por diante, como madrinha de tropilha. $»^{29}$

\section{Sombra}

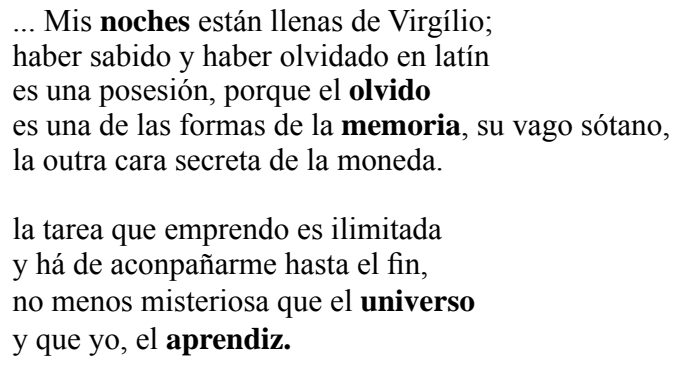

26 Antonio Candido é citado por Elida Lois, em seu Estudio Filológico Preliminar in: GÜIRALDES, op. cit., p. LX. 27 GÜIRALDES, op. cit., p. 246.

28 Idem, pp. 248-9.

29 Idem, p. 251. 
"Tem é de se lhe dar outro nome para que o leitor não perceber logo. A Sombra, porque é uma projeção de todos nós. Olha, aquilo que tu próprio disseste há pouco de ela ser feita de pedaços dos outros." Helder Macedo, Vícios e Virtudes

Borges, neste fragmento nos remete ao seu universo, à sua biblioteca, em que o esquecer faz-se primordial para o rememorar e é no entrecruzamento memória e esquecimento que a Memória se constitui. O leitor é aprendiz e a Sombra é o difuso, onde o lembrar e o não lembrar estão sempre em presente alternância, constituindo todos os textos, intertextos e memórias. Se a Sombra, em Borges é a memória obscurecida, no caso seguinte ela aparece como projeção.

Em seu romance-ensaio de $2002^{30}$, o escritor transfronteiras Helder Macedo ${ }^{31}$ transita no gênero entre lugar para falar de Identidade Nacional, de Pátria, de História e histórias. Gênero entre lugar porque seu livro esboça ensaios de crítica literária nas entrelinhas, cita a desconstrução ${ }^{32}$, a metáfora de Jakobson ${ }^{33}$, enquanto destece a História portuguesa e seus principais ícones: Dom Sebastião, sua mãe Joana e insere dois escritores disputando a autoria do romance, enquanto o narrador é manipulado pela protagonista.

Mas ao falar da Sombra ${ }^{34}$ é que mais identificou sua escrita com a idéia do recorte, do universo: a projeção de todos nós, feita de pedaços dos outros. Não seria, então uma possível definição de um conceito sempre em andamento (como todos em Literatura Comparada $^{35}$ ), a noção do intertexto, esta mandala, esta memória circular?

Assim como o olvido de Borges é fundamental à construção da memória, também o é o esquecimento. E é no embaçamento dos olhos, na obliteração da memória que Don Segundo se faz mais presente.

A silhueta reduzida de meu padrinho apareceu na lombada. Pensei que era muito ligeiro. Não obstante, era ele, sentia-o porque, apesar da distância, não estava longe. Minha vista fixava-se energicamente naquele pequeno movimento no pampa sonolento. Já ia chegar ao alto do caminho e desaparecer. Foi-se reduzindo como se o cortassem por baixo em repetidos talhos. Sobre o ponto negro do chapéu, meus olhos aferraram-se, como para fazer perdurar aquele momento. Inútil, algo nublava meus olhos, talvez o esforço, e uma luz cheia de pequenas vibrações estendeu-se sobre a planura. Não sei que estranha sugestão me propunha a presença ilimitada de uma alma.

'Sombra', me repeti. Depois pensei quase violentamente em meu pai adotivo. Rezar? Deixar simplesmente fluir minha tristeza? Não sei quantas coisas se

30 MACEDO, Helder. Vícios e Virtudes. Rio de Janeiro: Record, 2002.

31 Digo transfronteiras porque o é do ponto de vista social e cultural. Nasceu na África do Sul, criou-se em Moçambique e São Tomé, jovem foi a Portugal e há quarenta anos vive em Londres, onde escreve poesias, romances, e ensaios críticos, pois que também é o titular da Cátedra de Camões do King's College.

32 Op. cit. p., 22.

33 Op. cit., p. 27.

34 Op. cit., p. 233.

35 A ementa da disciplina ministrada por Tania Franco Carvalhal é: "Literatura Comparada e Weltliteratur: conceitos em andamento". 
amontoaram em minha solidão. Mas são coisas que um homem jamais confessa. Concentrando minha vontade na execução de pequenos feitos, dei de rédeas a meu cavalo e, lentamente, fui para casa.

Me fui como quem se dessangra.

FIM

La Porteña, março de 1926.

Se a Sombra é a projeção de todos nós, Don Segundo são todos os gaúchos. Güiraldes foi além: converteu a Sombra em identidade nacional, tal como Helder Macedo. Neste caso, Sombra nada mais é que o mosaico de gentes e de paisagens ultrapassada em seu sentido inicial. E a narrativa cheia de amor pela terra se adensa neste final em que a Sombra aparece pela primeira vez, à exceção do título: o próprio Fábio Cáceres se dá conta de sua situação - sangra porque volta a ser guacho, abandonado, de certa forma pelo homem que representa todas as referências de sua vida. $\mathrm{O}$ escritor representa o paradoxo da identidade argentina nessa última e dolorida passagem: mesmo com a cultura adquirida e a transformação em homem culto, é na memória de Don Segundo, é na sua projeção, na Sombra, que a identidade se constitui. O que é o alheio, agora? Ser gaucho ou ser guacho? $\mathrm{O}$ que restou de seus amores?

Nada e tudo. O que se revela à luz desta narrativa é paradoxal como a figura de Güiraldes, de que o conhecimento do próprio só é possível conhecendo-se o alheio. A identidade se aprende com a alteridade. E a Sombra só existe se houver Luz.

\section{Palavras desiguais ou finais}

O ato de "sombrear" Don Segundo nada mais é do que buscar a memória do texto na intertextualidade guiraldiana, nada mais atravessado pela interdisciplinaridade deste romancista, contista, vanguardista, regionalista e cosmopolita, pintor, correspondente, dançarino de tango e violinista. Buscar em suas memórias, na sua biblioteca intelectual a nostalgia (sombra) de sua vida campeira/verdadeira (memória), para assim recompor seu percurso de argentino após ter todas as nacionalidades. Criar a argentinidade após Facundo, após Martín Fierro de fora para dentro, só após ter sido tudo o que poderia ser, antes de ser gaucho e guacho. Sua aldeia era o mundo: de Paris, umbigo do mundo à estância de seu pai, em San Antonio de Areco, interior argentino. Cavalga, pinta e escreve em La Porteña; dança o tango, declama e escreve em Montmartre. Nada mais intertextual, nada mais interdisciplinar. Nada mais regional, nada mais cosmopolita. Ser local é ser universal. Buscar a identidade local (regional) depois de viver o pertencimento alheio e encontrar o próprio no alheio. O íntegro no difuso, o manifesto, a identidade e o processo nacional no romance reconfigurador de suas próprias paisagens internas e eternas. Don Segundo e todas as suas sombras/memórias é a recherche du temps perdu de Güiraldes e, sem querer, do argentino e do latino-americano, sempre aislados de si mesmos, porque sempre no entre lugar Europa América.

Assim, acho que podemos dizer que Güiraldes se dispersou antes, e às suas memórias, para disseminar seu texto e formar a memória contida em Don Segundo e tornar o leitor desta memória mais uma sombra de sua infinita paisagem campeira. 
Referências

ANDRADE, Oswald. A Utopia Antropofágica - obras completas. São Paulo: Globo, 1990.

. Le plaisir du texte. Paris: Seuil, 1973.

BLASI, Alberto. Güiraldes: vida y escritura. In: GÜIRALDES, Ricardo. Don Segundo Sombra. Edición crítica, Paul Verdevoye, coordinator, $1^{a}$ reimp. Madrid; Paris; México; Buenos Aires; São Paulo; Lima; Guatemala; San José de Costa Rica; Santiago de Chile: ALLCA XX, 1997.

CARVALHAL, Tania Franco (coord.). Culturas, Contextos e Discursos. Porto Alegre:Editora da Universidade, 1999.

DÍAZ, Nilda. Don Segundo Sombra: pampa y camino. In: GÜIRALDES, Ricardo. Don Segundo Sombra. Edición crítica, Paul Verdevoye, coordinator, $1^{\text {a }}$ reimp. Madrid; Paris; México; Buenos Aires; São Paulo; Lima; Guatemala; San José de Costa Rica; Santiago de Chile: ALLCA XX, 1997.

GÜIRALDES, Ricardo. Don Segundo Sombra. Edición crítica, Paul Verdevoye, coordinator, $1^{\text {a }}$ reimp. Madrid; Paris; México; Buenos Aires; São Paulo; Lima; Guatemala; San José de Costa Rica; Santiago de Chile: ALLCA XX, 1997.

. Don Segundo Sombra. Porto Alegre: L\&PM, 1997. Tradução de Augusto Meyer.

. Don Segundo Sombra. Rio de Janeiro: Livraria Francisco Alves, 1981. Tradução de

Augusto Meyer.

- Xaimaca. Buenos Aires: Editorial Losada, 1953 (2 ed.).

HERNÁNDEZ, José. Martín Fierro. Buenos Aires: Karten, 1979.

LOIS, Elida. Estudio Filológico Preliminar. In: GÜIRALDES, Ricardo. Don Segundo Sombra. Edición crítica, Paul Verdevoye, coordinator, $1^{a}$ reimp. Madrid; Paris; México; Buenos Aires; São Paulo; Lima; Guatemala; San José de Costa Rica; Santiago de Chile: ALLCA XX, 1997.

MACEDO, Helder. Vícios e Virtudes. Rio de Janeiro: Record, 2002.

PERRONE-MOISÉS, Leyla. Literatura Comparada, Intertexto e Antropofagia. In:

Flores da Escrivaninha. São Paulo: Companhia das Letras, 1990.

RODRÍGUEZ-ALCALÁ, Hugo. Destinos. In: GÜIRALDES, Ricardo. Don Segundo Sombra. Edición crítica, Paul Verdevoye, coordinator, $1^{\text {a }}$ reimp. Madrid; Paris; México; Buenos Aires; São Paulo; Lima; Guatemala; San José de Costa Rica; Santiago de Chile: ALLCA XX, 1997.

SÁBATO, Ernesto. Mito y Realidad de Don Segundo Sombra. In: GÜIRALDES, Ricardo. Don Segundo Sombra. Edición crítica, Paul Verdevoye, coordinator, $1^{\mathrm{a}}$ reimp. Madrid; Paris; México; Buenos Aires; São Paulo; Lima; Guatemala; San José de Costa Rica; Santiago de Chile: ALLCA XX, 1997. 